\title{
1 The effect of peat and wood fly ash on the porosity of mortar
}

Rissanen Jouni ${ }^{a}$, Giosuè Chiara ${ }^{b}$, Ohenoja Katja ${ }^{a}{ }^{*}$, Kinnunen Paivo ${ }^{a}$, Marcellini Mirco ${ }^{b}$, Maria Letizia Ruello ${ }^{b}$, Tittarelli Francesca $^{\text {bc }}$, \& Illikainen Mirja ${ }^{a}$

a Fibre and Particle Engineering, Faculty of Technology, PO Box 4300, 90014, University of Oulu, Finland

${ }^{\mathrm{b}}$ Department of Materials, Environmental Sciences and Urban Planning - SIMAU, Università Politecnica delle Marche, UdR INSTM, 60131 Ancona, Italy

c ISAC-CNR Bologna, Italy

* Corresponding author, e-mail: katja.ohenoja@oulu.fi

\section{Abstract}

Fluidized bed combustion fly ash (FBCFA), notably different from regular (coal) fly ash, is a promising industrial side stream to be used as a supplementary cementitious material (SCM). Peat and wood are important sources of biomass for energy production in Nordic countries and generate formidable amounts of un-used ash yearly. Two FBCFAs from the co-combustion of peat and wood, fly ash from coal combustion, and limestone filler were used to replace 10 wt \%, 20 wt $\%$, and 40 wt \% of cement in mortar specimens. The compressive strength, porosity, water absorption, water vapor permeability, and drying shrinkage of the mortars were measured and compared. It was found that in almost all properties FBCFAs outperformed un-reactive limestone filler. Compared to coal fly ash, FBCFAs produced mortars with comparable compressive strength although with higher porosity, water absorption, and water vapor permeability.

Keywords: biomass fly ash, fluidized bed combustion, porosity, capillary water absorption, water vapor permeability, drying shrinkage

1. Introduction

Fly ash originating from fluidized bed combustion (FBC) is a significant side stream of energy production that does not have well established reutilization practices yet. The FBC method is suitable for different fuel types with a variable quality, such as biomass, peat, municipal waste and coal. Fluidized bed combustion fly ashes (FBCFA) resulting from renewable sources can be expected to be an available and relevant material in the future. This may not be the case for 
pulverized coal combustion fly ashes, as societies are striving to reduce $\mathrm{CO}_{2}$ emissions and their dependency on fossil fuels. It has been already reported that in some regions demand for supplementary cementitious materials is already higher than their production [1]. From the viewpoint of a circular economy, it is important to find a variety of applications to utilize side streams instead of landfilling them as waste. One promising application for FBCFA is to use it as a partial cement replacement material, as several studies have already shown [2-7]. The utilization of fly ashes can also reduce the $\mathrm{CO}_{2}$ emissions of concrete $[1,8,9]$. Ideally, fly ash should be utilized near its production site, because it has been studied [1] that long transportation distance of this material can produce enough $\mathrm{CO}_{2}$ emissions to outweigh the benefits of the utilization.

Porosity is an important property of cement-based materials due to its effect on hardened-state properties, including strength, water absorption, and durability. It is well known that partial cement replacement by unreactive fillers can increase the porosity of mortars/concretes as the water to cement ratio (W/C) of the paste increases. However, FBCFAs differ from most traditional fillers and fly ashes due to their characteristics: they usually possess highly irregular particle shape $[2,3,5,7,10-16]$, which can affect the workability and microstructure of the hardened cement paste matrix. Additionally FBCFAs can possess hydraulic properties [3], meaning that material can react with water and produce cementitious reaction products. Fly ashes from the pulverized coal combustion have usually pozzolanic properties, meaning that material contains high amount of reactive silica that can react together with calcium hydroxide to form calcium silicate hydrate, the main reaction product of cement. On the other hand, in addition to pozzolanic properties, fly ashes from pulverized coal combustion can contain also hydraulic properties if material contains enough reactive calcium. These type of fly ashes may demonstrate similar self-cementitious properties as FBCFAs.

Only a few studies have investigated how cement replacement by FBCFAs effects the porosity [17-19] of mortars/concretes and, consequently, the other related properties, such as water absorption [20], water vapor permeability, and drying shrinkage [20-23] . In addition, there are also few studies investigating how cement replacement by FBCFAs affects the properties of air-entrained concrete $[20,24,25]$.

It should be noted that almost all previous studies on the aforementioned topics were conducted on fly ashes originated from the combustion of coal, and only one [20] dealt with non-coal derived fly ash. It is still uncertain how well the results obtained by FBCFAs from coal combustion can be applied to FBCFAs from non-coal based fuels. Since it is known that coal-derived fuels often have high sulfur content, which requires limestone injection to eliminate SOx emissions, the amount of injected limestone can be as much as $30 \%-50 \%$ of burned fuel [26]. It is reasonable to assume that a different fuel source together with a higher amount of injected limestone can have a significant effect on the physical 
and chemical characteristics of formed fly ashes. Additionally, the effect of fluidized bed combustion fly ash on water vapor permeability has not been studied before. Therefore, there is a need to further study the effect of fly ash from fluidized bed combustion of peat and wood on porosity and properties related to it.

This research aims to investigate the effect of cement replacement by FBCFAs from the co-combustion of wood and peat on the porosity, water absorption, water vapor permeability, and drying shrinkage of mortars. Additionally, specimens in which cement was replaced by coal fly ash or limestone filler are prepared and tested as references.

\section{Materials and Methods}

\subsection{Materials}

Fly ash samples from the circulating fluidized bed combustion of wood and peat were obtained from two different plants. Both fly ashes had promising chemical characteristics for utilization as cement replacement material, but they differed in particle morphology and bulk density. The fly ashes, referred to as FBCFA-1 and FBCFA-2, were not exposed to humid conditions prior to experiments. Fly ash originating from pulverized coal combustion (PFA) and limestone filler (LF) (CA 100, Cava Gola della Rossa) were used as reference materials for comparison.

The type of cement used was CEM II/A-LL 42,5 R (Colacem), according to standard SFS-EN 197-1 [27]. The aggregate was a commercial sand ranging in size from 0 to $3 \mathrm{~mm}$ (SABBIA0/3, Esincalce). The used super plasticizer (SP) was an acrylic polymer based (Dynamon SP1, Mapei).

Both FBCFAs had slightly higher particles size than cement (Fig. 1). The median particle sizes of FBCFA-1 and FBCFA-2 were $39.7 \mu \mathrm{m}$ and $15.9 \mu \mathrm{m}$, respectively, whereas the median particle size of cement was $10.2 \mu \mathrm{m}$. The particle size distributions of PFA and LF were really close to that of cement; their median particle sizes were $10.4 \mu \mathrm{m}$ and $6.1 \mu \mathrm{m}$, respectively. 


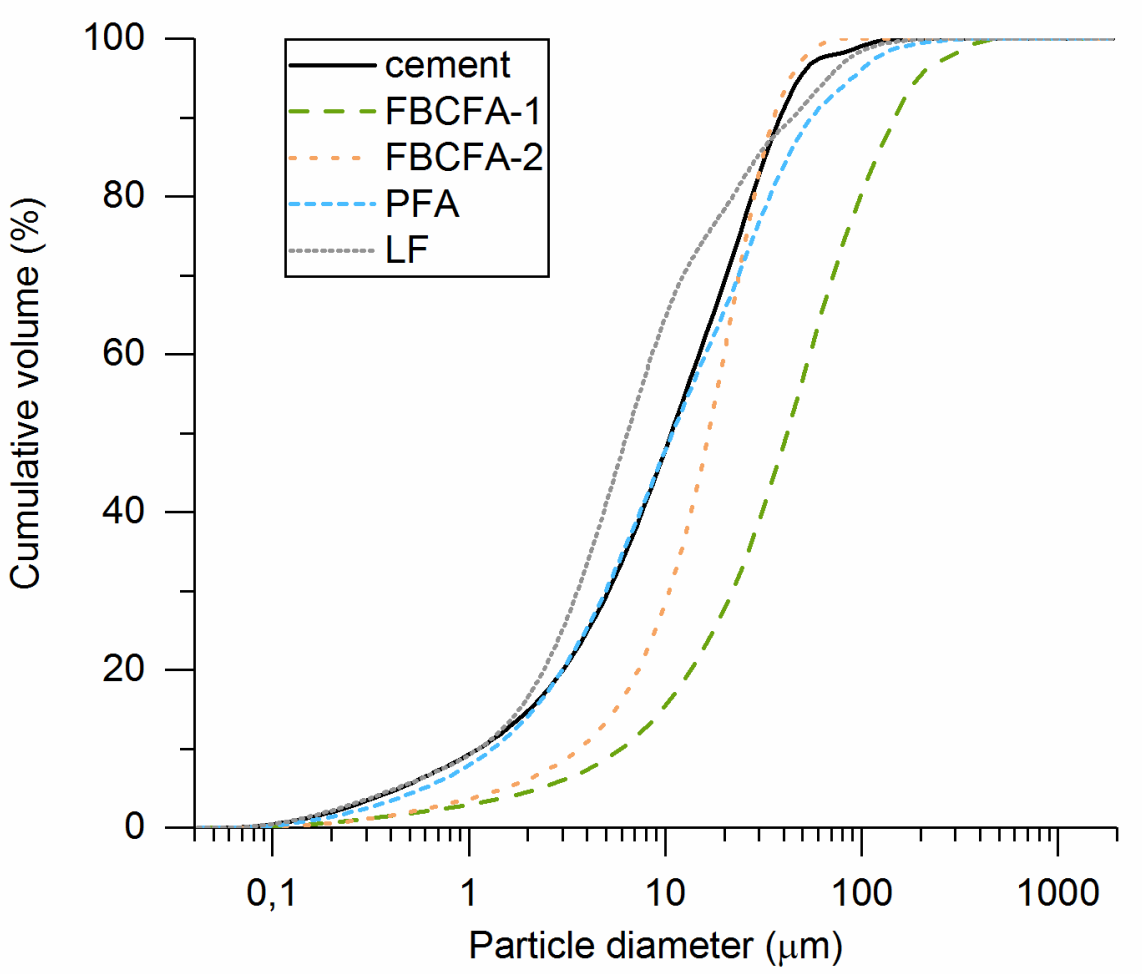

Fig. 1. Particle size distribution of cement and replacement materials.

Both FBCFAs used in this study were mainly composed of $\mathrm{Ca}, \mathrm{Si}, \mathrm{Al}$, and Fe, but containing also $\mathrm{P}, \mathrm{S}, \mathrm{Mg}$, and $\mathrm{K}$ (Table 1). The content of $\mathrm{Cl}$ was $0.1 \%$ for both FBCFAs, which satisfies the requirement of fly ash standard EN 450-1 [28]. SO content of FBCFA-1 was $2.1 \%$, which was below the limit of fly ash standard EN-450-1 (3.0\%) while the $\mathrm{SO}_{3} \mathrm{content}$ of FBCFA-2 (3.5\%) slightly exceeded that limit. P2O5 content as well as content of alkalis (calculated as $\mathrm{Na}_{2} \mathrm{O}$ equivalent) of both FBCFAs was below the limits of fly ash standard EN-450-1. FBCFA-1 contained $2.5 \%$ of free CaO, whereas FBCFA2 only the $0.1 \%$. Loss on ignition was low for both materials, indicating a low content of carbon unburned. The PFA was composed mainly of $\mathrm{Ca}, \mathrm{Si}$, and $\mathrm{Al}$, but it also contained some Fe and small quantities of other elements. Due to high calcium content of PFA, it is likely that this ash contains also hydraulic properties in addition to pozzolanic properties. Loss on ignition was $2.9 \%$. Unsurprisingly, LF seems to almost pure calcium carbonate, since it has CaO content of $97.5 \%$. This conclusion is also supported by the fact that LF has very high LOI value $(44.0 \%)$ as the calcium carbonate decompose roughly at the temperature of $825^{\circ} \mathrm{C}$. The chemical composition of the cement is typical for cement type CEM II/A-LL $42,5 \mathrm{R}$, consisting mainly of $\mathrm{Ca}$, $\mathrm{Si}$, and $\mathrm{Al}$. The loss on ignition value for cement was $5.2 \%$, which was probably due to the added limestone. 
97 Table 1. Chemical composition (wt \%) of materials.

\begin{tabular}{lllllll} 
& FBCFA-1 & FBCFA-2 & PFA & LF & cement & sand \\
\hline $\mathrm{CaO}$ & 16.3 & 12.0 & 42.6 & 97.5 & 65.5 & 79.8 \\
$\mathrm{SiO}_{2}$ & 41.8 & 30.8 & 33.4 & 0.2 & 19.1 & 17.8 \\
$\mathrm{Al}_{2} \mathrm{O}_{3}$ & 13.1 & 15.1 & 10.1 & 0.1 & 5.0 & 0.8 \\
$\mathrm{Fe}_{2} \mathrm{O}_{3}$ & 13.6 & 26.7 & 5.5 & 0.1 & 2.5 & 0.4 \\
$\mathrm{Na}_{2} \mathrm{O}$ & 2.1 & 1.1 & 0.8 & 0.0 & 0.4 & 0.0 \\
$\mathrm{~K}_{2} \mathrm{O}$ & 2.3 & 1.6 & 1.2 & 0.0 & 0.9 & 0.3 \\
$\mathrm{MgO}$ & 2.5 & 2.5 & 2.0 & 1.0 & 1.3 & 0.6 \\
$\mathrm{P}_{2} \mathrm{O}_{5}$ & 3.5 & 4.9 & 0.3 & 0.0 & 0.3 & 0.1 \\
$\mathrm{TiO}_{2}$ & 0.5 & 0.4 & 0.5 & 0.0 & 0.2 & 0.0 \\
$\mathrm{SO}_{3}$ & 2.1 & 3.5 & 1.9 & 0.2 & 3.5 & 0.1 \\
$\mathrm{Cl}_{\text {Free CaO }}$ & 0.1 & 0.1 & 0.0 & 0.0 & 0.1 & 0.0 \\
Loss on ignition $950{ }^{\circ} \mathrm{C}$ & 0.3 & 1.5 & 2.9 & 44.0 & 5.2 & 6.2
\end{tabular}

98

\subsection{Methods}

\subsubsection{Characterization of materials}

The chemical composition of the materials was analyzed by X-ray fluorescence method (XRF). The analysis was done from melt-fused tablets using a wavelength dispersive XRF spectrometer (AxiosmAX, PANanalytical). The tablets were prepared by melting $1.5 \mathrm{~g}$ of the examined material with $7.5 \mathrm{~g}$ of X-ray flux Type $66: 34$ (66\% Li2B4O7 and 34\% LiBO2) at $1150^{\circ} \mathrm{C}$. Loss on ignition at $950^{\circ} \mathrm{C}$ was determined using thermogravimetric analysis (prepASH, Precisa Gravimetrics AG). The free CaO content of the FBCFAs was analyzed according to standard EN 451-1 [29]. The particle size distribution of materials was investigated using a laser diffraction particle size analyzer (LS 13 320, Beckman Coulter). Measurements were done in wet mode in isopropanol, and the data were analyzed using the Fraunhofer optical model.

\subsubsection{Preparation of mortar specimens}

The mix design of the reference specimen was based on European cement testing standard EN 196-1 [30] with a few modifications as a bigger batch size, the use of a SP. Instead of CEN-standard sand, different sand product having different chemical composition, particle size distribution, and moisture content, was used. Aggregate sand was composed mainly from calcium containing phases, whereas CEN-standard sand is composed almost completely from silica. Particle size of aggregate sand ranged between 0 to $3 \mathrm{~mm}$, whereas CEN-standard sand ranges between 0.08 and 

standard is $0.2 \%$.

In the specimens, FBCFA-1, FBCFA-2, PFA, or LF replaced the 10,20 , or $40 \%$ by weight of cement. In the mortar specimen labelled as FBCFA-1 10\%, 10\% of the cement was replaced by FBCFA-1; the same logic applies to label the other mortar specimens. The mix design of the different mortars is presented in Table 2. In order to ensure the same amount of sand and effective water hydrating cement, the amounts of sand and water were accordingly adjusted in every mix as reported in Table 2 .

Table 2. Mix design of mortars.

\begin{tabular}{|c|c|c|c|c|c|c|c|c|c|c|c|}
\hline Sample & $\begin{array}{c}\text { sand } \\
\left(\mathrm{kg} / \mathrm{m}^{3}\right)\end{array}$ & $\begin{array}{l}\text { cement } \\
\left(\mathrm{kg} / \mathrm{m}^{3}\right)\end{array}$ & $\begin{array}{c}\text { water } \\
\left(\mathrm{kg} / \mathrm{m}^{3}\right)\end{array}$ & $\begin{array}{c}\text { super } \\
\text { plasticizer } \\
\left(\mathrm{kg} / \mathrm{m}^{3)}\right.\end{array}$ & $\begin{array}{l}\text { FBCFA-1 } \\
\qquad\left(\mathrm{kg} / \mathrm{m}^{3}\right)\end{array}$ & $\begin{array}{c}\text { FBCFA-2 } \\
\left(\mathrm{kg} / \mathrm{m}^{3}\right)\end{array}$ & $\begin{array}{c}\text { PFA } \\
\left(\mathrm{kg} / \mathrm{m}^{3}\right)\end{array}$ & $\begin{array}{c}\mathrm{LF} \\
\left(\mathrm{kg} / \mathrm{m}^{3}\right)\end{array}$ & $\begin{array}{c}\text { Water/ } \\
\text { Cement }\end{array}$ & $\begin{array}{c}\text { Water/ } \\
\text { Powder }^{\mathrm{a}}\end{array}$ & Sand/Powder ${ }^{\mathrm{a}}$ \\
\hline Reference & 1516 & 505 & 252 & 1.36 & 0 & 0 & 0 & 0 & 0.50 & 0.50 & 3.00 \\
\hline FBCFA-1 $10 \%$ & 1512 & 454 & 252 & 1.97 & 50 & 0 & 0 & 0 & 0.56 & 0.50 & 3.00 \\
\hline FBCFA-1 $40 \%$ & 1501 & 300 & 250 & 4.1 & 200 & 0 & 0 & 0 & 0.83 & 0.50 & 3.00 \\
\hline FBCFA-2 10\% & 1514 & 454 & 253 & 3.66 & 0 & 50 & 0 & 0 & 0.56 & 0.50 & 3.00 \\
\hline FBCFA-2 20\% & 1515 & 404 & 253 & 7.69 & 0 & 101 & 0 & 0 & 0.63 & 0.50 & 3.00 \\
\hline FBCFA-2 $40 \%$ & 1516 & 303 & 253 & 9.22 & 0 & 202 & 0 & 0 & 0.83 & 0.50 & 3.00 \\
\hline PFA $10 \%$ & 1514 & 454 & 252 & 1.05 & 0 & 0 & 50 & 0 & 0.56 & 0.50 & 3.00 \\
\hline PFA $20 \%$ & 1510 & 403 & 252 & 1.29 & 0 & 0 & 101 & 0 & 0.63 & 0.50 & 3.00 \\
\hline PFA $40 \%$ & 1505 & 301 & 251 & 1.42 & 0 & 0 & 201 & 0 & 0.83 & 0.50 & 3.00 \\
\hline LF $10 \%$ & 1513 & 454 & 252 & 1.38 & 0 & 0 & 0 & 50 & 0.56 & 0.50 & 3.00 \\
\hline LF $20 \%$ & 1507 & 402 & 251 & 1.42 & 0 & 0 & 0 & 101 & 0.63 & 0.50 & 3.00 \\
\hline LF $40 \%$ & 1504 & 301 & 251 & 1.46 & 0 & 0 & 0 & 200 & 0.83 & 0.50 & 3.00 \\
\hline
\end{tabular}

${ }^{a}$ Powder includes cement and possible cement replacement material

To prepare mortars, the ingredients were mixed in buckets using a drill. First cement, fillers, water and SP were mixed for 2 minutes $(\min )$. Then sand was slowly added and the mortar mixed for further 4-9 min. To manufacture FBCFA-2 $20 \%$ and FBCFA-4 $40 \%$ specimens, an extra amount of SP had to be added to ensure proper workability. After mixing, the workability of the mixtures was evaluated by measuring the diameter of the spread mortar according to the flow table method described in EN 1015-3 standard [31] with slight modifications. In this method, a truncated, cone-shaped mold (100 base diameter, $70 \mathrm{~mm}$ top diameter, and $60 \mathrm{~mm}$ height) is first placed on a jolting table and 
filled with mortar. Next, the mold is removed and the table is jolted 15 times in 15 seconds. After that, the diameter of the mortar is measured from two directions at right angles, and the average of these measurements is calculated. This procedure was repeated, and, finally, the average diameter was reported. The workability of the mortars was adjusted to give a $12 \pm 1 \mathrm{~cm}$ spread on the flow table test.

Finally, the mortars were cast in molds according to EN 1015-11 standard [32]. Next, the specimens were sealed with a plastic film to ensure a relative humidity $(\mathrm{RH})$ of $95 \pm 5 \%$. After 2 days, the specimens were demolded and kept sealed (RH $95 \pm 5 \%$ ) for the following 5 days. After 21 days, the mortars were exposed to an $\mathrm{RH}$ of $65 \pm 5 \%$. The curing of the specimens was conducted at a temperature $(\mathrm{T})$ of $20 \pm 1^{\circ} \mathrm{C}$.

\subsubsection{Properties of hardened mortars}

The compressive strength of the mortars was measured after $28 \pm 1$ days of curing, according to EN 1015-11 standard [32] with a hydraulic press (Galdabini).

The porosity was analyzed using a mercury intrusion porosimeter (MIP) (Pascal 240, Thermo Fischer). Analysis were performed on 3 fragments of the specimens, originating from 28 days compressive strength measurements.

The capillary water absorption and capillary water absorption coefficient $(A C)\left(\mathrm{kg} / \mathrm{m}^{2} \cdot \mathrm{s}^{0.5}\right)$ of the mortar specimens were analyzed according to standard EN 15801 [33]. In this method, a cubic mortar specimen (40 x $40 \times 40 \mathrm{~mm})$, sawn from a mortar prism, is placed on a wet bedding layer. The water amount absorbed through the area of the cube's $(\mathrm{Qi})\left(\mathrm{kg} / \mathrm{m}^{2}\right)$ face is determined by weighting the specimen after certain time intervals. The AC is determined from the linear part of the plot in which Qi is presented as a function of the square root of time $\left(s^{0.5}\right)$. The AC is a slope of line, which is fitted to the first five data points, which are measured during the first 60 minutes of experiment.

A water vapor permeability test was performed according to standard EN 1015-19 [34]. Cylindrical specimens were prepared $(\mathrm{d}=12.5 \mathrm{~cm}, \mathrm{~h}=3.0 \mathrm{~cm})$. After 28 days of curing, the curved sides of the specimens were sealed to a specimen holder so that water vapor, released under controlled conditions by using a saturated solution of potassium nitrate $\left(\mathrm{KNO}_{3}\right)$, was able to diffuse only through the flat ends of the mortar specimens. Inside the specimen holder, the $\mathrm{RH}$ was $93 \pm 3 \%$, and the temperature was $20 \pm 2{ }^{\circ} \mathrm{C}$, while outside, the $\mathrm{RH}$ and $\mathrm{T}$ were $50 \pm 5 \%$ and $20 \pm 2{ }^{\circ} \mathrm{C}$, respectively. Before the analysis of porosity, capillary water absorption and water vapor permeability, the specimens were dried in an oven at $60{ }^{\circ} \mathrm{C}$ until they reached constant mass. The reported results are the average values from three 

(Fig. 2).

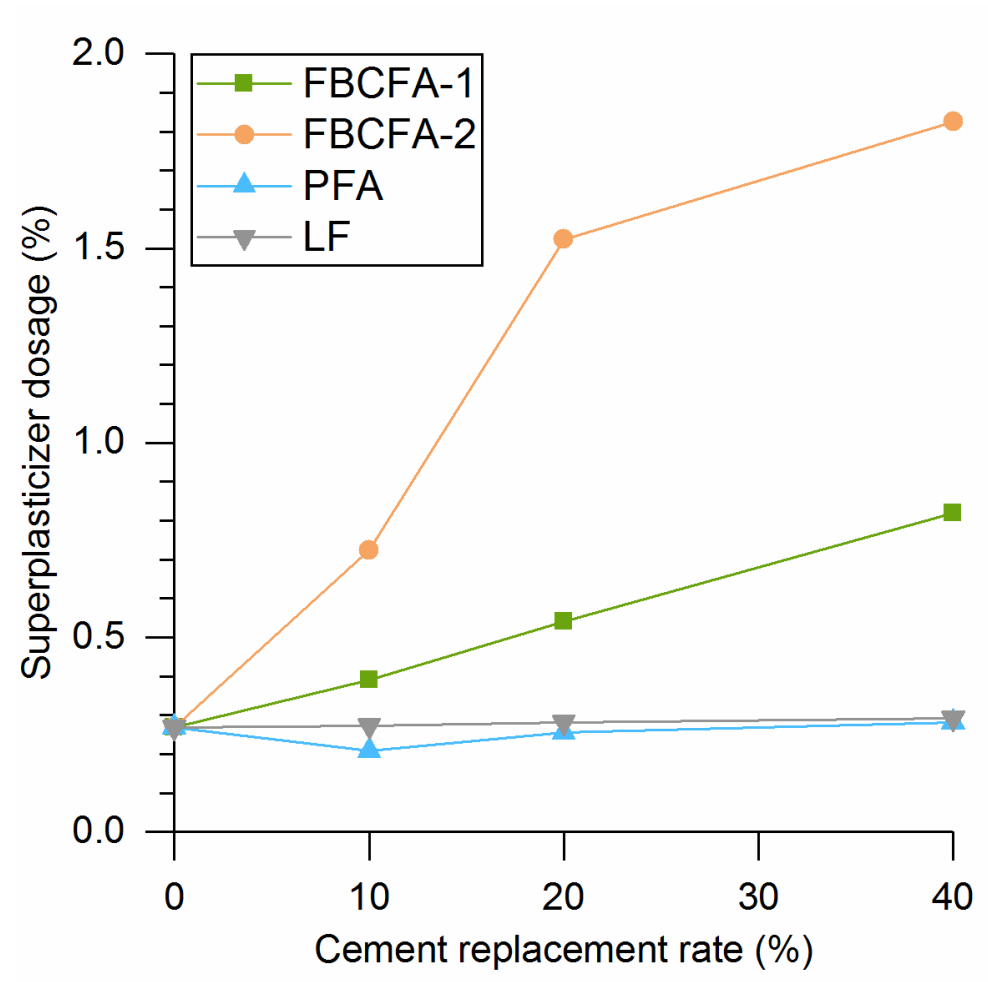

\subsection{Workability of mortars}

Fig. 2 shows that both FBCFAs required a much higher dosage of super plasticizer than reference mortar to obtain similar workability and the amount of SP increased with the replacement level. These results are well in line with other studies, which have reported increased water requirement $[5,6,10,36-38]$ or increased SP dosage [7] caused by FBCFAs due to the higher water absorption typical forbiomass ash $[39,40]$. In particular, mortars with FBCFA-2 required more SP than mortars with FBCFA-1. In our previous study [10], ash samples obtained from the same power plants were compared concluding that the share of highly irregularly shaped ash particles varies among ashes affecting workability in different way. Therefore, it is reasonable to assume that FBCFA-2 contains more irregularly shaped ash particles, although this is hard to quantify, than FBCFA-1, which increases SP dosage. The amount of added SP in the mortars containing PFA and LF was quite close to that in the reference mortar indicating that the effect of these materials on workability was low 
Fig. 2. Super plasticizer dosage of mortar specimens, as a percentage of powder's (cement and possible replacement material) mass.

\subsection{Porosity of mortars}

The cumulative porosity of the mortar increased compared to the reference specimen when cement was replaced with FBCFAs, but without a clear trend (Fig. 3a and b). The number of pores with $d>0.1 \mu \mathrm{m}$ (Fig. 4a and b) especially increased in all specimens with FBCFA. Furthermore, in FBCFA-2 20\% and FBCFA-2 40\% specimens, the number of pores with d $<0.1 \mu \mathrm{m}$, slightly decreased (Fig. 4b). These results are in line with those of Zhao et al., which also reported increased number of pores in the size range of 0.01-0.1 $\mu \mathrm{m}$ [17] when FBCFA from coal gangue combustion was used as a cement replacement material. Similarly, Lin et al. reported that cement replacement using FBCFA from coal combustion increased total porosity; however, in their case, porosity was especially increased in the size range of 1-10 $\mu \mathrm{m}$ [18]. Also Janowska-Renkas et al. reported significant increase in total porosity when 30 and $45 \%$ of cement was replaced with FBCFA form coal [19]. The increased number of small pores in specimens containing FBCFAs could be caused by highly irregularly shaped ash particles. It is possible that these ash particles contain pores, which are not filled with hydration products during the 28 day curing time, as reported for paper ash by [41].

The PFA did not have much effect on the porosity of the specimens compared to the reference specimen regardless of the replacement rate (Figs. 3c and 4c). It is possible that because PFA has a similar particle size distribution to cement and smooth particle morphology, it has good filler properties, which mitigates the increase in porosity due to increased W/C. Apparently, as the replacement rate increases, the hydraulic and pozzolanic properties of PFA can still compensate the increase in porosity caused by an increased W/C.

When LF replaced $10 \%$ of the cement, there was only a small decrease in total porosity. However, when higher replacement rates of $20 \%$ or $40 \%$ were used, the porosity of the mortars clearly increased (Figs. $3 d$ and $4 d$ ) due to the increased W/C. Based on the MIP results, in LF 40\% specimen cement replacement especially increased the number of large pores (diameter $>0.3 \mu \mathrm{m}$ ), which may have a more detrimental effect on strength properties.

It should be noted that the MIP analysis was performed on a pore size range of $8 \mathrm{~nm}$ to $11 \mu \mathrm{m}$. This means that small gel pores $(<8 \mathrm{~nm})$, larger capillary pores $(>11 \mu \mathrm{m})$, and pores from entrained air were not detected by this method, although there may be differences among the specimens in this pre-mentioned pore sizes, which may affect mortar properties. 

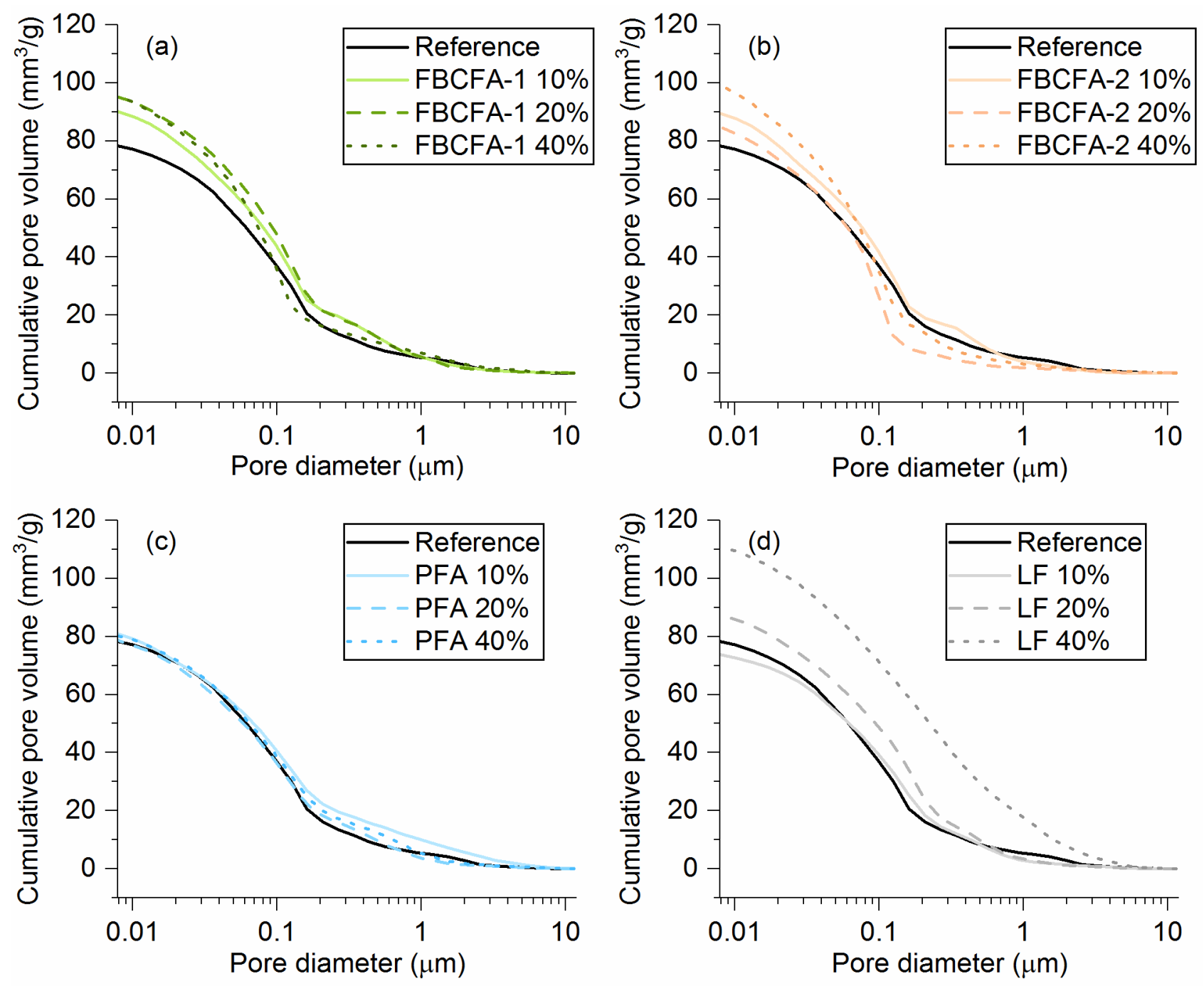

Fig. 3. Cumulative pore volume of mortars. 

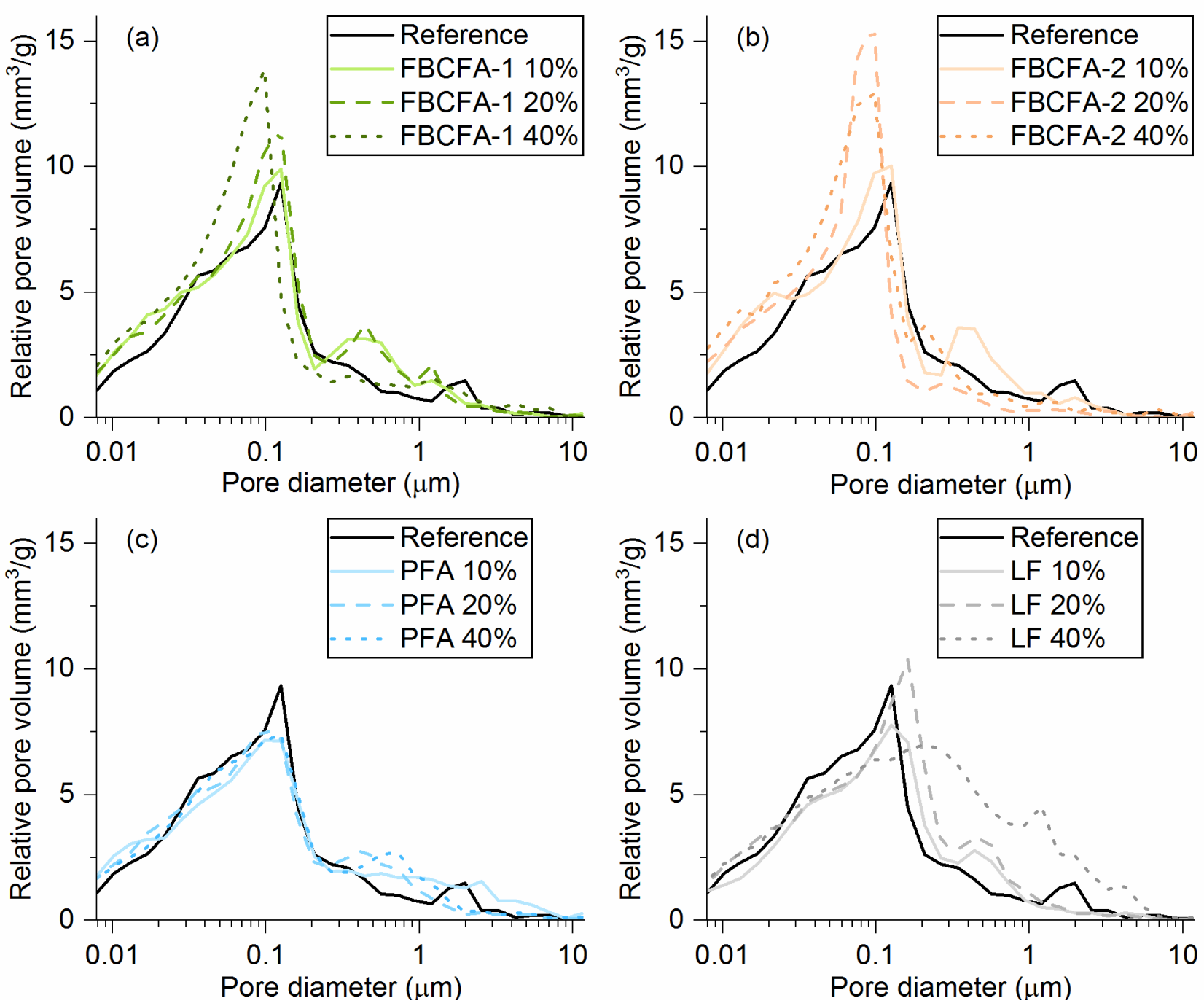

Fig. 4. Relative pore volume of mortars.

Total porosity of mortar specimen (Fig. 5) was in line with cumulative pore volume (Fig. 3). Both FBCFs in generally

increased total porosity as replacement rate increased. There were however few exceptions to this trend. In FBCFA-1

total porosity did not increased when replacement rate was increased from $20 \%$ to $40 \%$. In the case of FBCFA-2 total

porosity decreased from $18.1 \%$ to $17.4 \%$ as replacement increased from $10 \%$ to $20 \%$. Increased total porosity has been also when cement has been replaced using FBCFA originating from combustion of coal gangue [17]. Cement replacement using PFA did not had significant effect on total porosity (Fig. 5). When LF was to used as cement replacement material at $10 \%$ replacement rate it decreased porosity, but when replacement ratios increased, also the total porosity increased significantly (Fig. 5). 


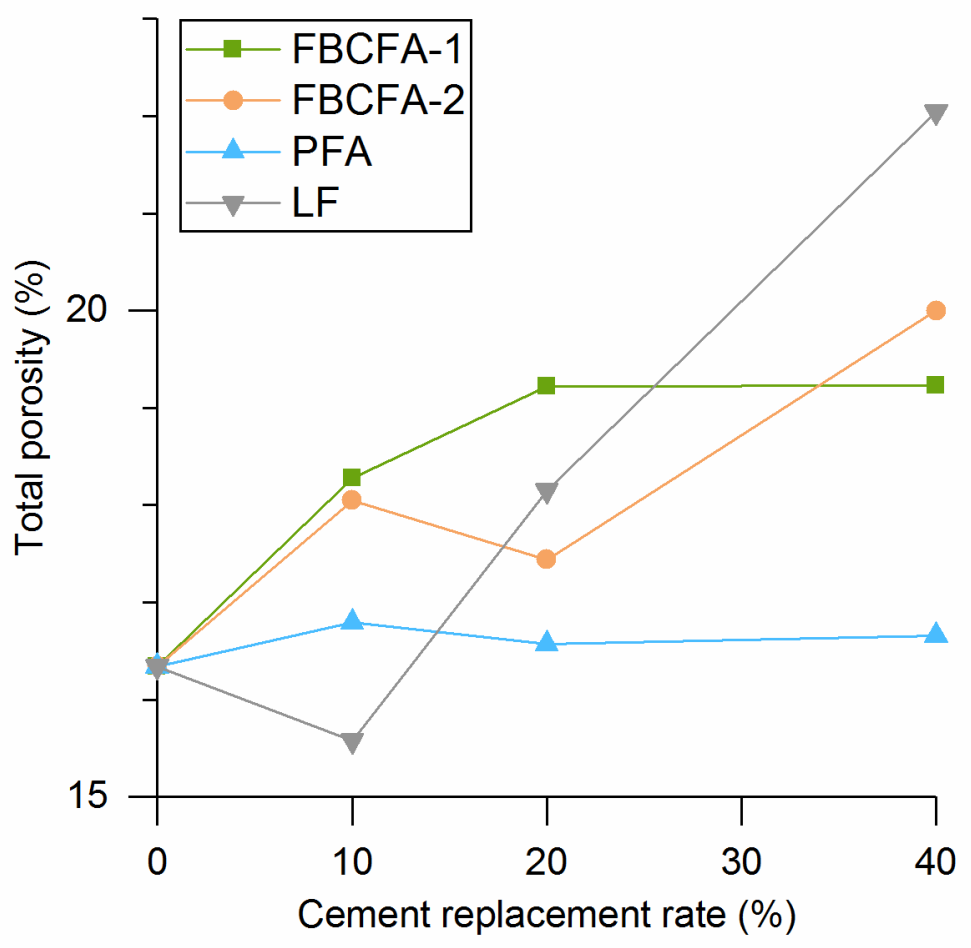

Fig. 5. Total porosity of mortars

\subsection{Compressive strength of mortars}

Based on the compressive strength measurements, it seems that both FBCFAs are reactive materials and they contribute

to strength development in a way similar to PFA. When more than $10 \%$ of the cement was replaced, they clearly outperformed unreactive LF.

FBCFA-1 clearly decreased the compressive strengths as replacement rate increased (Fig. 6). The behavior of FBCFA-2 was more ambiguous; at a $10 \%$ replacement rate, strength of the corresponding mortar was at the same level of that with FBCFA-1 and LF, but when the replacement rate was increased to $20 \%$, strength increased to near the strength of the reference sample (48.2 MPa). It is possible that good performance of FBCFA-2 at $20 \%$ replacement rate was due to reduced porosity on small pore size. Finally, at the replacement rate of $40 \%$, FBCFA-2 mortar still reached a strength of 39.6 MPa, similar to that of PFA $40 \%$ mortar and only $18 \%$ lower than that of the reference specimen. Cement replacement by PFA produced lower compressive strength than the reference specimen at every replacement rate (Fig. 6). From all the PFA-containing specimens, PFA $10 \%$ had the best performance, whereas the compressive strengths of PFA $20 \%$ and PFA $40 \%$ were slightly lower. Although PFA did not reach compressive strengths as high as the reference specimen, it clearly had hydraulic properties, since the compressive strengths were much higher than with 
unreactive LF. In generally total porosity correlated quite well with the compressive strength within different replacement materials, not with PFA. It is possible that hydration products of PFA develops weaker binder matrix they have only limited effect on porosity.

The compressive strengths of the mortars containing LF decreased as the share of LF increased (Fig. 6). This was expected because LF is an unreactive filler material, unlike FBCFAs and PFA. The compressive strengths of $10 \%$ LF specimens were quite close to other specimens in which the same replacement ratio was used, but when the replacement ratio was higher, strengths were clearly lower than with other materials.

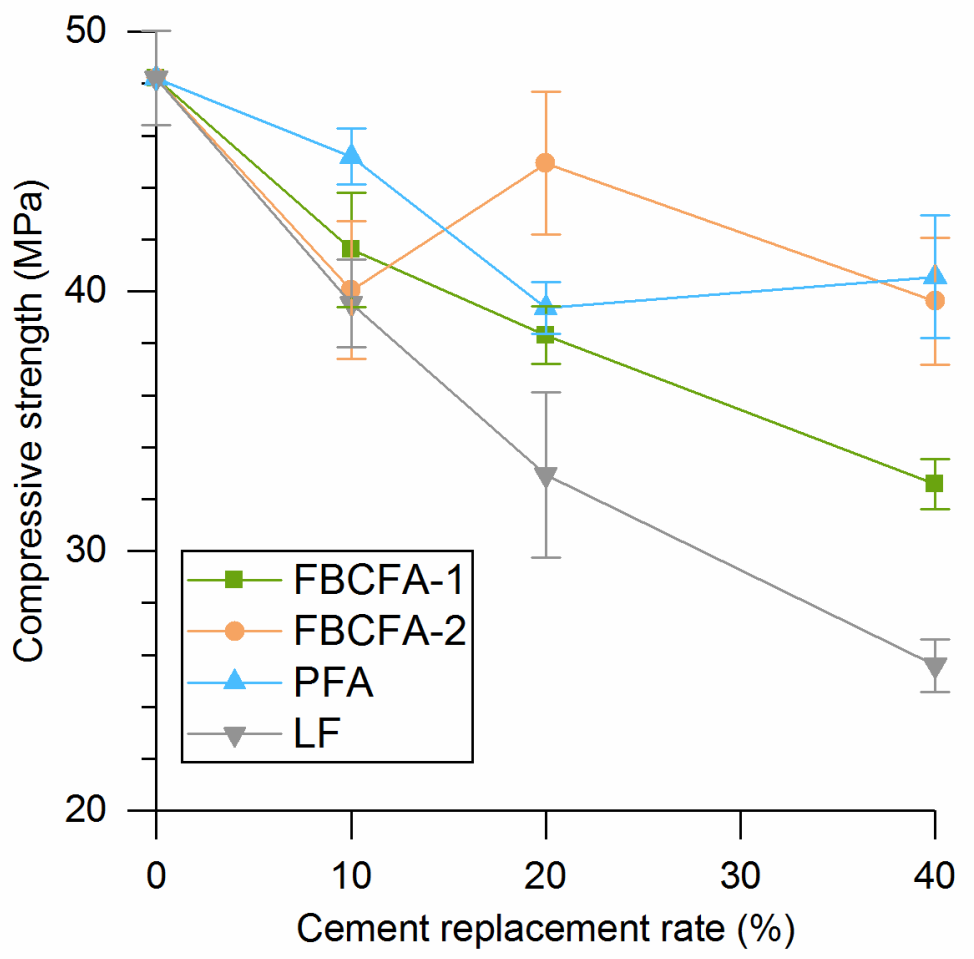

Fig. 6. Compressive strength of mortars after 28 days of hardening.

3.4 Capillary water absorption of mortars

The capillary water absorption curves presented in Fig. 7 can be divided into two parts; the first linear part is related to the filling of bigger capillary pores, whereas the second non-linear part is related to the filling of smaller pores [42-45]. The capillary water absorption coefficient (CA) presents the rate of water absorption and is determined from the linear part of the curve. The capillary water absorption curve also shows the total amount of absorbed water, which is related to the total porosity, pore size, and connectivity of the pores [45]. 
Regarding the reference specimen, the capillary water absorption curve had not yet stabilized at the end of the experiment, which means that the specimen had the potential to absorb even more water if the test had continued. With a few exceptions, FBCFAs generally increased the capillary water absorption of the mortars (Figs. 7a and b) compared to the reference specimen, whereas the effect on the water absorption coefficient was more limited (Fig. 8). FBCFA-1 $10 \%$ absorbed almost the same amount of water during the experiment as the reference specimen, whereas the total water absorptions of FBCFA-1 $20 \%$ and FBCFA-1 $40 \%$ were clearly higher. The mortar specimens containing FBCFA-1 had slightly higher water absorption coefficients than the reference specimen (Fig. 8). The water absorption of the specimens containing FBCFA-2 was similar to the specimens with FBCFA-1 (Fig. 7). The total amounts of absorbed water in FBCFA-2 10\% and FBCFA-2 20\% were slightly higher than in the reference specimen, whereas FBCFA-2 40\% had the highest amount of absorbed water in this study. However, the capillary water absorption coefficients of FBCFA-2 $10 \%$ and FBCFA-2 $40 \%$ specimens were really close to the reference specimen, whereas in FBCFA-2 20\%specimen, the water absorption coefficient was clearly lower (Fig. 8). It is possible that, although FBCFA increases the porosity of the specimens, it had only a limited effect on the water absorption rate because the ashes mainly increased the number of small pores (0.01-0.2 $\mu \mathrm{m}$ diameter). Apparently, these small pores do not have a significant impact on the rate of water absorption. However, with enough time, these small pores were also filled with water, which led to a higher amount of absorbed water at the end of experiment. Results of this study are in line with those of Nagrockienè and Daugèla who studied the effect of cement replacement using 0-30\% wood fly ash (combustion method was not mentioned) on water absorption of concrete. They found that up to $15 \%$ replacement rate water absorption was slightly decreased. At higher replacement rates ( $\geq 20 \%$ ) water wood fly ash slightly increased water absorption [46]. On the other hand results of this study differ from those of Ipatti who studied the effect of cement replacement with peat fly ash and coal fly ash on water tightness of concrete and came to conclusion that peat fly ash slightly improved the water tightness while coal fly ash made concrete slightly less water tight, however differences between specimen were only marginal [20].

The effect of PFA on the amount of absorbed water was quite limited, and there was no clear trend between the amount of absorbed water and the replacement rate (Fig. 7c). This result is well in line with the fact that these specimens had quite similar microstructures according to the MIP results (Figs. $3 c$ and 4c). However, the results of the MIP experiments indicated that there could be a small increase in the amount of large capillary pores in these specimens, which could explain the slightly increased water absorption coefficients (Fig. 8c) caused by cement replacement using PFA. Results differ significantly from the study of Hussain et al. in which cement replacement using 0-60\% coal fly ash significantly 
275 increased water absorption while wood fly ash caused much smaller increase in water absorption with similar 276 replacement rates [47].

277 Cement replacement using more than 10\% LF seemed to increase the water absorption of the specimens; this result is 278 generally in line with the MIP results (Figs. 3d and 4d). However, in the MIP experiment, the difference between the 279 total porosities of LF $20 \%$ and $40 \%$ was quite high, although the difference in the amount of total absorbed water was 280 almost insignificant. The effect of LF on the capillary water absorption coefficient was clearer; the increase in the coefficient was proportional to the cement replacement rate (Fig. 8d). This is in line with the porosity results (Figs. $3 \mathrm{~d}$ and 4d), which indicated that cement replacement using LF increased the amount of large pores when the replacement rate was higher than $10 \%$. Apparently, cement replacement using unreactive filler material increases the amount of large capillary pores more than when reactive replacement materials such as FBCFAs or PFA are used. Consequently, this also leads to an increased rate of water absorption. 

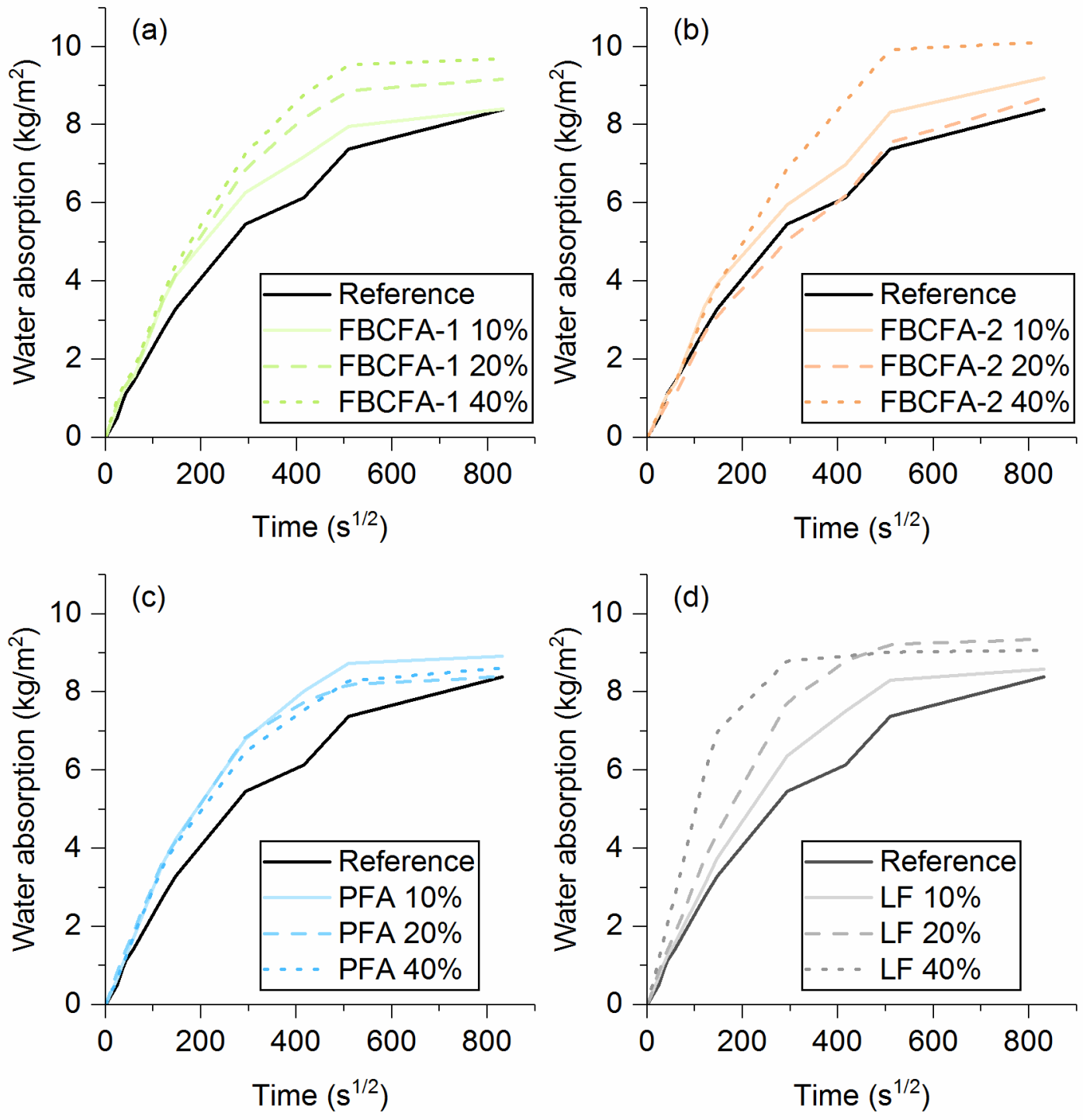

Fig. 7. Capillary water absorption of mortars. 


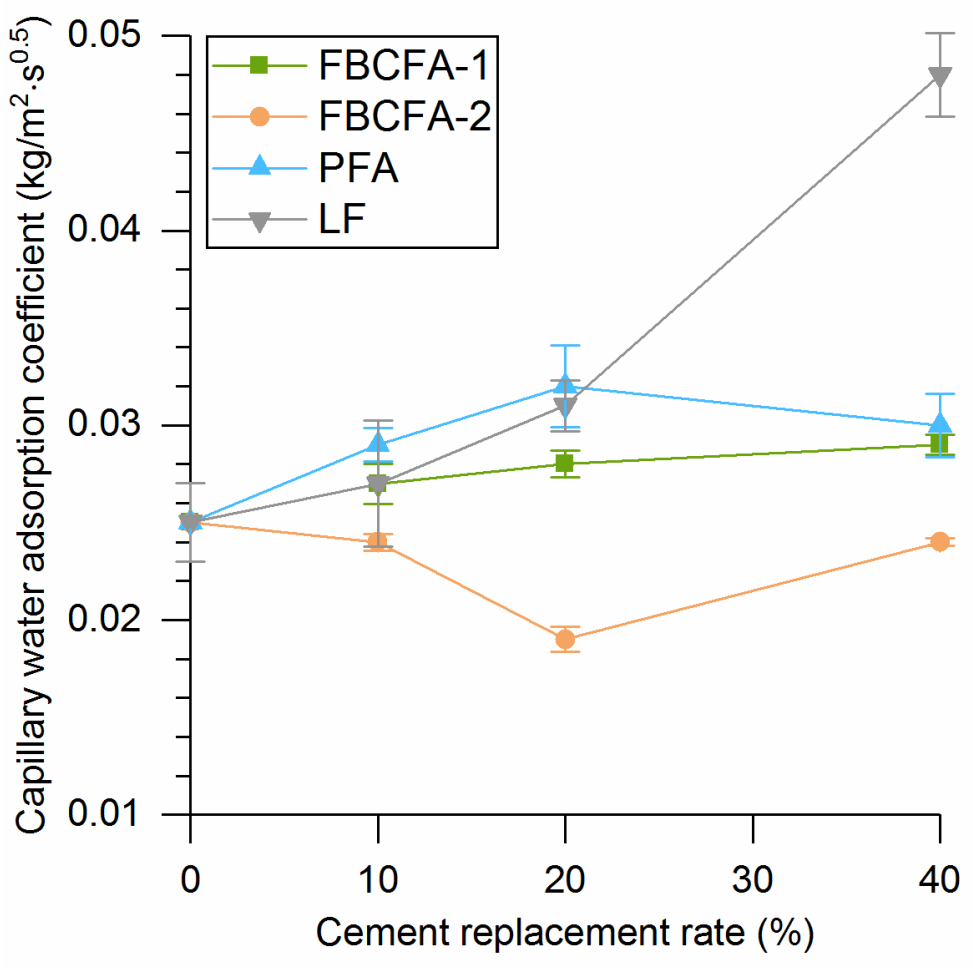

Fig. 8. Capillary water absorption coefficients of mortars.

\subsection{Water vapor permeability of mortars}

In most of the specimens, the cement replacement materials lowered the water vapor resistance factors compared to the reference specimen, which indicates an increased permeability to water vapor (Fig. 9).

Cement replacement by FBCFA-1 clearly lowered the water vapor resistance factors as the replacement rate increased, and the results were almost identical with unreactive LF (Fig. 9). In mortars containing FBCFA-1 decreased water vapor resistance factor correlated quite well with increase in total porosity (Fig. 5). In a similar way, FBCFA-2 decreased the water vapor resistance factor of the mortar, but there was no clear trend related to the replacement rate; for some reason, the lowest resistance factor was measured in specimen FBCFA-2 20\% (Fig. 9). Additionally, in the case of FBCFA2 there was no clear correlation with total porosity. The results could indicate that an increased number of small pores, observed in mortar specimens in which FBCFAs were used, also contributed to water vapor permeability, meaning that water vapor can diffuse through material more easily. 
decreased, but it is not clear if this decrease is significant, since deviation between the specimens was quite high.

Apparently, the overall effect of PFA on the pore structure of the mortars is relatively low, since results from the MIP, capillary water absorption, and water vapor permeability experiments show only a low correlation with the cement replacement rate. It is possible that reaction products from hydraulic and pozzolanic reactions can fill the pores in the cement paste matrix and decrease the permeability of the water vapor to the level of the reference specimen.

When cement was replaced using LF, the water vapor resistance factor clearly decreased incrementally as the replacement rate increased (Fig. 9). Obviously, this was due to increased total (Fig. 5) porosity and pore size, which was caused by increased W/C.

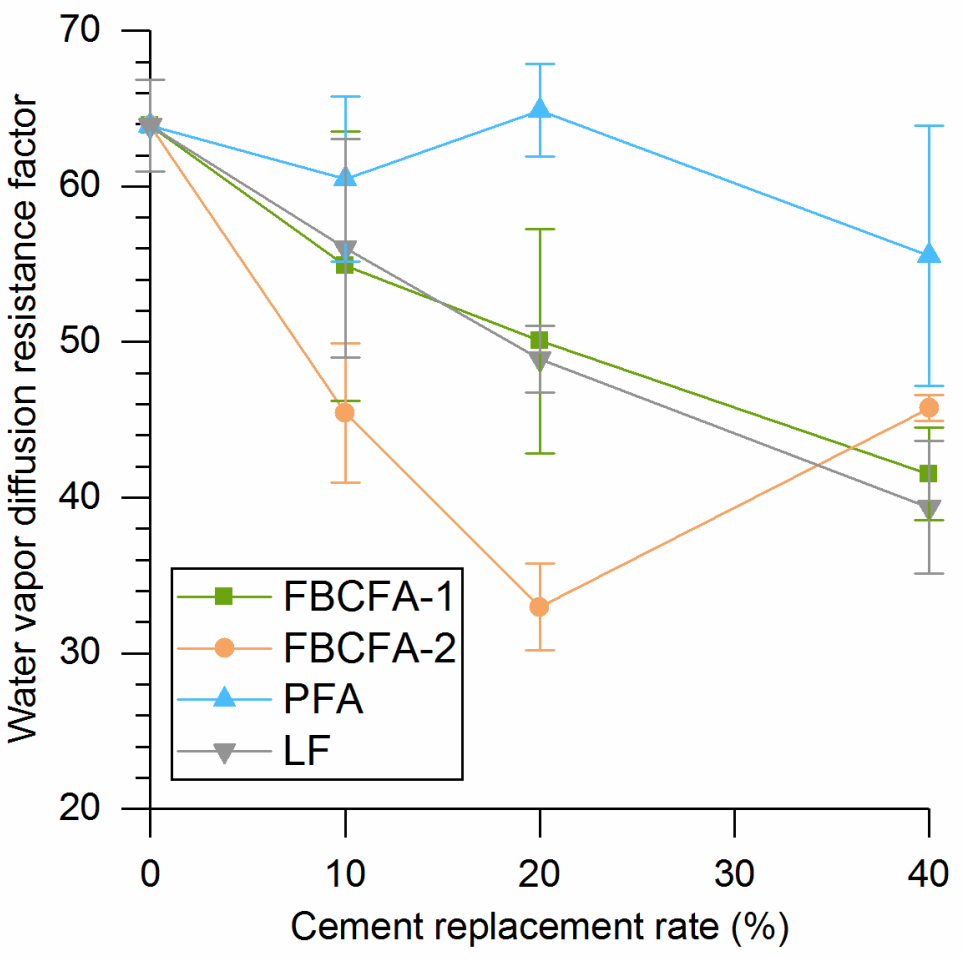

Fig. 9. Water vapor diffusion resistance factors of mortars.

3.6 Shrinkage and mass loss of mortar

FBCFAs and PFA did not had significant effect on shrinkage of mortars whereas LF seemed slightly decrease the shrinkage compared to reference specimen (Fig. 10). The shrinkage measurements were performed by several operators that may have induced some variation to measurement data. However, measurement data gives general trend and magnitude of mortars drying shrinkage. 
It is well known that drying shrinkage is mainly caused by the loss of physically absorbed water from calcium silicate hydrate. However, the loss of free water from larger pores does not cause significant shrinkage. Only when water is lost from smaller capillary pores, it causes negative internal pressure, resulting in shrinkage. This could explain why the mortars with FBCFAs and PFA exhibited similar drying shrinkage than the reference specimen, although their mass loss clearly increased with an increasing replacement rate (Fig. 11).

In the case of FBCFAs, it seems that the cement replacement using these ashes does not affect significantly drying shrinkage (Figs. 9a and b). Similarly, at the study of Ipatti there was no significant difference between drying shrinkage of reference concrete and concrete in which $37 \%$ of cement was replaced by peat fly ash [20]. On the contrary, mass loss seemed to increase as the replacement rate increased. Apparently, FBCFAs react at a much slower rate than cement, which leaves more free water in the material. Free water can probably exit easily from these mortars due to their increased porosity.

Similarly, cement replacement using PFA has no significant effect on drying shrinkage. Apparently, pozzolanic and hydraulic reactions caused by PFA lowered the amount of free water, which resulted in mass loss values close to those of the reference specimen, especially at replacement rates of $10 \%$ and $20 \%$. These results conflict with those found from other studies in which non-convenional fly ashes are compared to coal fly ash. Ipatti reported that increased drying shrinkage of concrete when $59 \%$ of cement was replaced suing coal fly ash [20]. On the other hand Wu et al. reported that conventional coal fly ash decreased the length change of mortars significantly. When coal fly ash from circulating fluidized bed combustion (CFBC) was used together with conventional coal fly ash length change increased as the share of CFBC increased [23].

When cement was replaced by unreactive LF, the specimens exhibited the lowest shrinkage (Fig. 9d) although their mass loss was the highest (Fig. 10d). These specimens contain more free water than other specimens do because LF does not react with water. The specimens also have high porosity, which may have increased the rate of mass loss. Apparently, cement replacement using LF increases the size of capillary pores, which decreases the drying shrinkage. Additionally cement replacement with LF reduced the cement paste content of specimens, which also reduced shrinkage. 

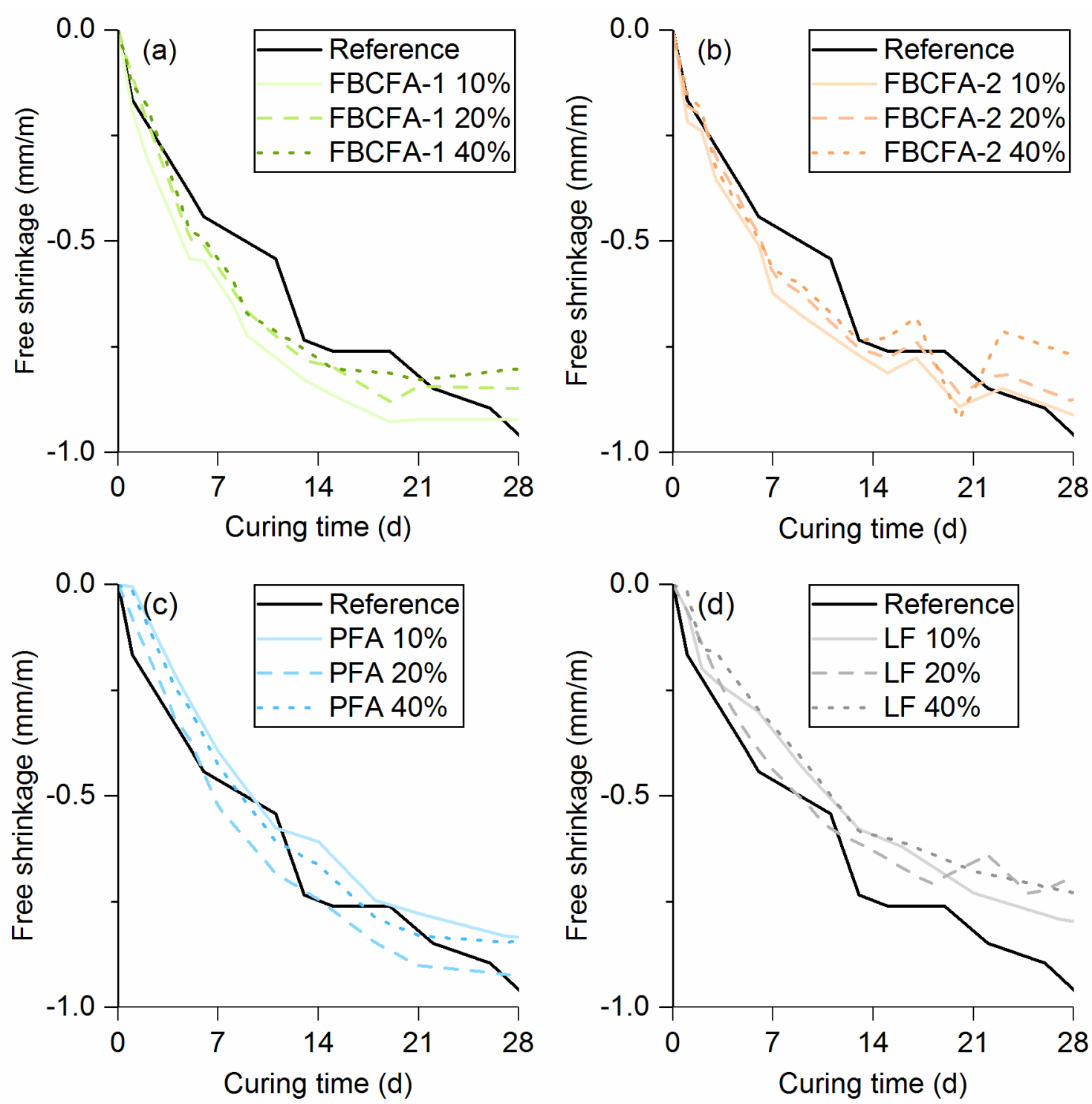

Fig. 10. Free shrinkage $(\mathrm{mm} / \mathrm{m})$ of mortars. 

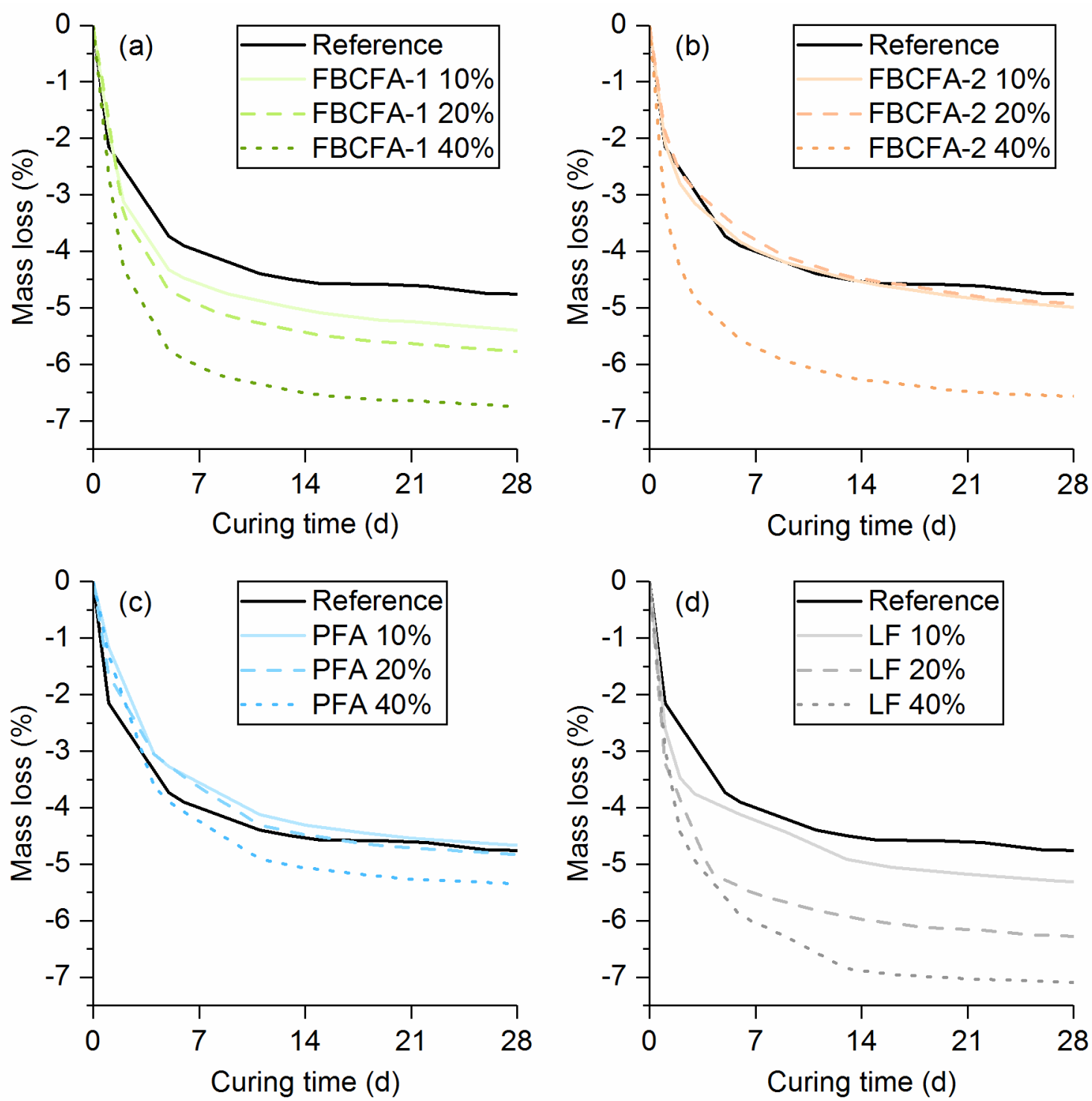

Fig. 11. Mass loss (\%) of mortars.

4. Conclusions

Untreated fluidized bed combustion fly ashes(FBCFAs) from the combustion of peat and wood could be utilized as supplementary cementitious material if a sufficient amount of super plasticizer (SP) is used to ensure proper workability, keeping the water/powder ratio constant. In this study, specimen FBCFA-2 $40 \%$ had the highest requirement for (SP). At the water/powder ratio of 0.5 , for this specimen SP dosage of $1.8 \%$ (from the mass of powders) was enough to produce mortar that could be easily cast to molds. 
For replacement up to $10 \%$ FBCFAs, the porosity is clearly increased. However, pores induced by FBCFAs had smaller diameters than pores induced by unreactive limestone filler (LF). These small pores increased the amount of capillary absorbed water as well as water vapor permeability. However, these small pores had a limited effect on the rate of capillary water absorption.

Despite the increased porosity, the studied FBCFAs increase the mechanical properties of mortars as fly ash from coal combustion (PFA), and both FBCFAs clearly outperformed unreactive LF in terms of compressive strength.

Cement replacement using FBCFAs and PFA did not had significant effect on drying shrinkage whereas LF slightly deceased drying shrinkage.

\section{Acknowledgements}

This work is a part of the MINSI project (A70189), which is supported by the European Regional Development Fund (ERDF) and Finnish companies including Fortum Waste Solutions, Pohjolan Voima, Oulun Energia, SSAB, and Stora Enso. Jouni Rissanen gratefully acknowledges the financial support from the Fortum Foundation and Tauno Tönning's Foundation. Ms. Roberta Marchetti, Mr. Jarno Karvonen, Mr. Jani Österlund, Mr. Roberto Mancini, Mr. Orlando Favoni, and Mr. Juho Rasmus are acknowledged for their contributions to the laboratory work.

\section{References}

[1] S.A. Miller, Supplementary cementitious materials to mitigate greenhouse gas emissions from concrete: can there be too much of a good thing?, J. Clean. Prod. 178 (2018) 587-598. doi:10.1016/j.jclepro.2018.01.008.

[2] J. Zhao, D. Li, S. Liao, D. Wang, H. Wang, P. Yan, Influence of mechanical grinding on pozzolanic characteristics of circulating fluidized bed fly ash (CFA) and resulting consequences on hydration and hardening properties of blended cement, J. Therm. Anal. Calorim. 132 (2018) 1459-1470. doi:10.1007/s10973-018-7103-4.

[3] J. Rissanen, K. Ohenoja, P. Kinnunen, M. Illikainen, Partial replacement of portland-composite cement by fluidized bed combustion fly ash, J. Mater. Civ. Eng. 29 (2017). doi:10.1061/(ASCE)MT.1943-5533.0001899.

[4] A. Pavoine, D. HARBEC, T. Chaussadent, A. TAGNIT-HAMOU, L. Divet, Impact of alternative cementitious material on the mechanical and transfer properties of concrete, Mater. J. 111 (2014) pp 251-261.

[5] X. Li, Q. Chen, K. Huang, B. Ma, B. Wu, Cementitious properties and hydration mechanism of circulating fluidized bed combustion (CFBC) desulfurization ashes, Constr. Build. Mater. 36 (2012) 182-187. doi:10.1016/j.conbuildmat.2012.05.017.

[6] G. Sheng, J. Zhai, Q. Li, F. Li, Utilization of fly ash coming from a CFBC boiler co-firing coal and petroleum coke in Portland cement, Fuel. 86 (2007) 2625-2631. doi:10.1016/j.fuel.2007.02.018.

[7] V. Sata, C. Jaturapitakkul, K. Kiattikomol, Influence of pozzolan from various by-product materials on mechanical properties of high-strength concrete, Constr. Build. Mater. 21 (2007) 1589-1598. doi:10.1016/j.conbuildmat.2005.09.011.

[8] E.R. Teixeira, R. Mateus, A.F. Camões, L. Bragança, F.G. Branco, Comparative environmental life-cycle analysis of concretes using biomass and coal fly ashes as partial cement replacement material, J. Clean. Prod. 112 (2016) 2221-2230. doi:10.1016/j.jclepro.2015.09.124.

[9] K.-H. Yang, Y.-B. Jung, M.-S. Cho, S.-H. Tae, Effect of supplementary cementitious materials on reduction of CO2 emissions from concrete, J. Clean. Prod. 103 (2015) 774-783. doi:10.1016/j.jclepro.2014.03.018. 
[10] J. Rissanen, K. Ohenoja, P. Kinnunen, M. Romagnoli, M. Illikainen, Milling of peat-wood fly ash: Effect on water demand of mortar and rheology of cement paste, Constr. Build. Mater. 180 (2018) 143-153. doi:10.1016/j.conbuildmat.2018.05.014.

[11] X. Chen, J. Gao, Y. Yan, Y. Liu, Investigation of expansion properties of cement paste with circulating fluidized bed fly ash, Constr. Build. Mater. 157 (2017) 1154-1162. doi:10.1016/j.conbuildmat.2017.08.159.

[12] D. Zheng, D. Wang, D. Li, C. Ren, W. Tang, Study of high volume circulating fluidized bed fly ash on rheological properties of the resulting cement paste, Constr. Build. Mater. 135 (2017) 86-93. doi:10.1016/j.conbuildmat.2016.12.127.

[13] T. Wu, M. Chi, R. Huang, Characteristics of CFBC fly ash and properties of cement-based composites with CFBC fly ash and coal-fired fly ash, Constr. Build. Mater. 66 (2014) 172-180. doi:10.1016/j.conbuildmat.2014.05.057.

[14] Y. Xia, Y. Yan, Z. Hu, Utilization of circulating fluidized bed fly ash in preparing non-autoclaved aerated concrete production, Constr. Build. Mater. 47 (2013) 1461-1467. doi:10.1016/j.conbuildmat.2013.06.033.

[15] G. Sheng, Q. Li, J. Zhai, Investigation on the hydration of CFBC fly ash, Fuel. 98 (2012) 61-66. doi:10.1016/j.fuel.2012.02.008.

[16] I. Demir, R.E. Hughes, P.J. DeMaris, Formation and use of coal combustion residues from three types of power plants burning Illinois coals, Fuel. 80 (2001) 1659-1673. doi:10.1016/S0016-2361(01)00028-X.

[17] J. Zhao, D. Li, S. Liao, D. Wang, H. Wang, P. Yan, Influence of mechanical grinding on pozzolanic characteristics of circulating fluidized bed fly ash (CFA) and resulting consequences on hydration and hardening properties of blended cement, J. Therm. Anal. Calorim. 132 (2018) 1459-1470. doi:10.1007/s10973-018-7103-4.

[18] K.-L. Lin, T.-W. Cheng, C.-H. Ho, Y.-M. Chang, K.-W. Lo, Utilization of Circulating Fluidized Bed Fly Ash as Pozzolanic Material, Open Civ. Eng. J. 11 (2017). doi:10.2174/1874149501711010176.

[19] E. Janowska-Renkas, J. Kowalska, G. Janus, A. Kaliciak, Cement-fly ash mortars durability, with fly ash from fluidized bed boilers and conventional combustion, exposed to aggressive environment influence, in: MATEC Web Conf., Poland, 2018. doi:10.1051/matecconf/201817402006.

[20] A. Ipatti, Peat fly ash as a supplementary cementing material in concrete, Nord. Concr. Res. (1988) $152-166$.

[21] L. Osuská, R. Hela, Use of fluidized bed combustion fly ash as addition reducing shrinkage of concrete, Mater. Sci. Forum. 865 (2016) 141-144. doi:10.4028/www.scientific.net/MSF.865.141.

[22] W. Stevens, T. Robl, K. Mahboub, The cementitious and pozzolanic properties of fluidized bed combustion fly ash, 3rd World Coal Ash WOCA Conf. - Proc. (2009).

[23] T. Wu, M. Chi, R. Huang, Characteristics of CFBC fly ash and properties of cement-based composites with CFBC fly ash and coal-fired fly ash, Constr. Build. Mater. 66 (2014) 172-180. doi:10.1016/j.conbuildmat.2014.05.057.

[24] D. Józwiak-Niedźwiedzka, Estimation of Chloride Migration Coefficient in Air-Entrained Concretes Containing Fluidized Bed Combustion Fly Ash / Ocena Współczynnika Migracji Jonów Chlorkowych W Betonach Zawierajacych Popiół Fluidalny, Arch. Civ. Eng. 58 (2012) 25-38. doi:10.2478/v.10169-012-0002-3.

[25] M.A. Glinicki, M. Zielinski, Air void system in concrete containing circulating fluidized bed combustion fly ash, Mater. Struct. 41 (2008) 681-687. doi:10.1617/s11527-007-9273-6.

[26] R.J. Deschamps, Using FBC and Stoker Ashes as Roadway Fill: A Case Study, J. Geotech. Geoenvironmental Eng. 124 (1998) 1120.

[27] SFS-EN 197-1:en. Cement. Part 1: Composition, specifications and conformity criteria for common cements, (2012).

[28] SFS-EN 450-1:en. Fly ash for concrete - Part 1: Definition, specifications and conformity criteria, (2013).

[29] SFS-EN 451-1:2017:en. Method of testing fly ash. Part 1: Determination of free calcium oxide content, (2017).

[30] SFS-EN 196-1:2016:en. Methods of testing cement. Part 1: Determination of strength, (2016).

[31] SFS-EN 1015-3:en. Methods of test for mortar for masonry. Part 3: Determination of consistence of fresh mortar (by flow table), (1999).

[32] SFS-EN 1015-11:en. Methods of test for mortar for masonary. Part 11: Determination of flexural and compressive strength of hardened mortar, (1999).

[33] SFS-EN 15801:en. Conservation of cultural property. Test methods. Determination of water absorption by capillarity, (2010).

[34] SFS-EN 1015-19:en. Methods of test for mortar for masonry. Part 19: Determination of water vapour permeability of hardened rendering and plastering mortars, (1998).

[35] SFS-EN 12617-4:en. Products and systems for the protection and repair of concrete structures. Test methods. Part 4: Determination of shrinkage and expansion, (2002).

[36] D. Gazdič, M. Fridrichová, K. Kulísek, L. Vehovská, The Potential Use of the FBC Ash for the Preparation of Blended Cements, Procedia Eng. 180 (2017) 1298-1305. doi:10.1016/j.proeng.2017.04.292. 
[37] R. Rajamma, L. Senff, M.J. Ribeiro, J.A. Labrincha, R.J. Ball, G.C. Allen, V.M. Ferreira, Biomass fly ash effect on fresh and hardened state properties of cement based materials, Compos. Part B Eng. 77 (2015) 1-9. doi:10.1016/j.compositesb.2015.03.019.

[38] R. Rajamma, R.J. Ball, L.A.C. Tarelho, G.C. Allen, J.A. Labrincha, V.M. Ferreira, Characterisation and use of biomass fly ash in cement-based materials, J. Hazard. Mater. 172 (2009) 1049-1060. doi:10.1016/j.jhazmat.2009.07.109.

[39] C. Giosuè, A. Mobili, G. Toscano, M.L. Ruello, F. Tittarelli, Effect of Biomass Waste Materials as Unconventional Aggregates in Multifunctional Mortars for Indoor Application, Procedia Eng. 161 (2016) 655-659. doi:10.1016/j.proeng.2016.08.724.

[40] Fava Gabriele, Ruello Maria Letizia, Corinaldesi Valeria, Paper Mill Sludge Ash as Supplementary Cementitious Material, J. Mater. Civ. Eng. 23 (2011) 772-776. doi:10.1061/(ASCE)MT.1943-5533.0000218.

[41] S. Monosi, D. Sani, M. Letizia Ruello, Reuse of Paper Mill Ash in Plaster Blends [Abstract], Open Waste Manag. J. 5 (2012). doi:10.2174/1876400201205010005.

[42] Y. Benachour, C.A. Davy, F. Skoczylas, H. Houari, Effect of a high calcite filler addition upon microstructural, mechanical, shrinkage and transport properties of a mortar, Cem. Concr. Res. 38 (2008) 727-736. doi:10.1016/j.cemconres.2008.02.007.

[43] C. Giosuè, Q.L. Yu, M.L. Ruello, F. Tittarelli, H.J.H. Brouwers, Effect of pore structure on the performance of photocatalytic lightweight lime-based finishing mortar, Constr. Build. Mater. 171 (2018) 232-242. doi:10.1016/j.conbuildmat.2018.03.106.

[44] F. Tittarelli, C. Giosuè, A. Mobili, M.L. Ruello, Influence of binders and aggregates on VoCs adsorption and moisture buffering activity of mortars for indoor applications, Cem. Concr. Compos. 57 (2015) 75-83. doi:10.1016/j.cemconcomp.2014.11.013.

[45] A. Mobili, A. Belli, C. Giosuè, T. Bellezze, F. Tittarelli, Metakaolin and fly ash alkali-activated mortars compared with cementitious mortars at the same strength class, Cem. Concr. Res. 88 (2016) 198-210. doi:10.1016/j.cemconres.2016.07.004.

[46] D. Nagrockienè, A. Daugèla, Investigation into the properties of concrete modified with biomass combustion fly ash, Constr. Build. Mater. 174 (2018) 369-375. doi:10.1016/j.conbuildmat.2018.04.125.

[47] Z. Hussain, R. Maqsood, M.I. Din, S.M. Khan, A. Shahnaz, M. Rashid, S. Ameen, Enhanced mechanical properties of wood ash and fly ash as supplementary cementitious materials, Adv. Appl. Ceram. 116 (2017) 355-361. doi:10.1080/17436753.2017.1321274. 